\title{
A balança comercial do agronegócio brasileiro de 1989 a 2005
}

Geraldo Sant'Ana de Camargo Barros ${ }^{1}$

Simone Fioritti Silva ${ }^{2}$

Resumo: Este trabalho analisa a contribuição do agronegócio para o saldo comercial do Brasil. Uma nova classificação de balança comercial do agronegócio foi criada e usada para analisar os lados dos produtos exportados (representados pelos produtos agrícolas, produtos de origem animal e alimentos industrializados) e dos insumos importados (representados pelos fertilizantes) para o período de 1989 a 2005. Foram elaborados modelos de importação e exportação a fim de retratar e explicar o comportamento dessas variáveis, empregando a Análise de Auto-Regressões Vetoriais (Vector Autoregression Analysis - VAR). Pôde-se observar que um aumento de $1 \%$ na atratividade - dada pelo produto do câmbio e dos preços externos - impulsiona as exportações de produtos agrícolas não processados em 1,71\% imediatamente, estabilizando-se em $2 \%$ após alguns trimestres. A atratividade explica de $60 \%$ a $74 \%$ da variância dos erros de previsão dessas exportações. Nota-se que uma desvalorização cambial, por exemplo, aumenta mais as exportações de produtos do que as importações de fertilizantes. Além disso, um crescimento de $1 \%$ no PIB doméstico exerce impacto expressivo (convergindo em -1,7\%) de contenção das exportações dos produtos agrícolas.

\footnotetext{
${ }^{1}$ Professor Doutor da Escola Superior de Agricultura Luiz de Queiroz (Esalq/USP). E-mail: gscbarro@esalq.usp.br

${ }^{2}$ Mestre em Economia Aplicada pela Esalq/USP. E-mail: simone_fioritti@yahoo.com.br
} 
Palavras-chave: Balança comercial do agronegócio; produtos agrícolas; produtos animais; indústria de alimentos; fertilizantes; crescimento econômico; atratividade; exportações; importações; produtividade.

Abstract: This study aims to analyze the agribusiness contribution to Brazil's trade balance. A new classification of the agribusiness trade balance was proposed and used to analyze the aspects of the exported products -agricultural products, products of animal origin, industrialized foods and imported inputs - represented by fertilizers. Imports and exports vector autoregression models were used to explain the behavior of these variables. An increase of $1 \%$ in the attractiveness - product of the exchange rate by the international prices - boosts immediately the exports of non processed agricultural products by $1.71 \%$, stabilizing at $2 \%$ after some trimesters. The attractiveness explains 60 to $74 \%$ of the forecast error variances of these exportats. It is noted that an exchange rate devaluation stimulates more the exports of products than it does the fertilizer imports. Besides, an increase of $1 \%$ of the GDP has an expressive impact (converging into -1.7\%) on agricultural products exports.

Key-words: Agribusiness trade balance; agricultural products; animal products; food industry; fertilizers; economic growth; attractiveness; exports; imports; productivity.

Classificação JEL: Q17; Q18.

\section{Introdução}

Por meio de uma significativa revolução tecnológica, foram alcançados aumentos de produtividade que contribuíram para a competitividade e eficiência do agronegócio brasileiro. Seu desempenho - particularmente após o Plano Real - proporcionou, a partir dos anos 1990: (a) um crescimento da produção acompanhado de queda real dos preços aos consumidores, que muito beneficiou a sociedade como um todo, principalmente as camadas mais pobres da população, além de ter facilitado a manutenção das baixas taxas de inflação observadas no perío- 
do; (b) saldos comerciais que variaram entre 9 e 32 bilhões de dólares por ano, atenuando, assim, os déficits comerciais do País que, de outra forma, poderiam tornar-se insuportáveis para a economia.

No entanto, à medida que se distancia do momento da implantação do Plano Real, vai se generalizando a impressão de que é extremamente difícil juntar ao sucesso da estabilização (controle da inflação) um ritmo de crescimento econômico mais acelerado que promova aumento do emprego e do bem-estar da população como um todo. Estudos recentes têm indicado que uma aceleração no crescimento poderia comprometer as exportações, devido ao aumento da demanda interna pelos produtos que seriam exportados (BARROS et al., 2002). Maiores taxas de crescimento também resultariam em aumentos de importações. De ambas as formas, o fluxo de divisas para o País poderia ficaria comprometido. Acredita-se, ainda, que a alternativa das desvalorizações - além das dificuldades operacionais num regime de flutuação, como o brasileiro - pode resultar numa ruptura do controle inflacionário ao acirrar a disputa entre as demandas doméstica e externa. De qualquer forma, permanece a questão dos ganhos ou perdas associadas aos movimentos cambiais, num sentido ou outro, decorrentes da atuação das forças de mercado.

Torna-se, assim, importante a análise dos fatores explicativos da formação de superávits comerciais pelo agronegócio de sorte a que se possa antecipar a possibilidade de, a partir de algum ponto, passar a ocorrer conflitos entre a geração de tais superávits e a manutenção da inflação sob controle. Dessa forma, é necessário determinar as relações entre taxas de câmbio, taxa de crescimento do PIB, preços internacionais de commodities, assim como o comportamento da produtividade, com o superávit comercial do agronegócio.

Observando os sub-setores do agronegócio, pode-se notar que alguns têm contribuído significativamente ao desempenho exterior do setor.

Como mostra a Figura 1, o agronegócio brasileiro vem mantendo uma dependência relativamente estável na área de defensivos ao lado de uma dependência crescente no segmento de fertilizantes. Esse fato sinaliza que podem ocorrer situações em que o objetivo de aumento do superávit comercial não possa simplesmente ser alcançado por via da desvalorização cambial. 
Figura 1. Saldo dos fatores de produção

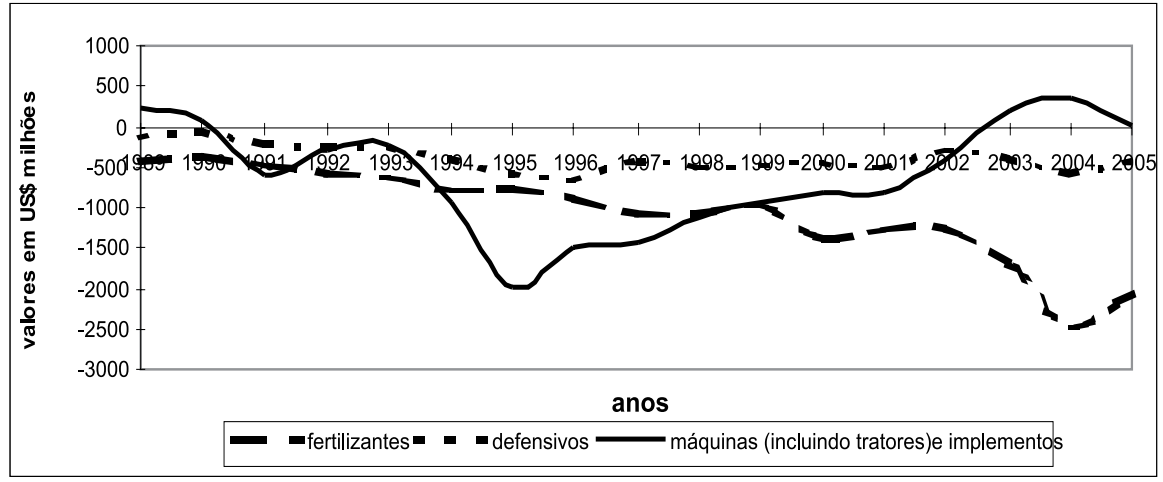

Fonte: Elaborado a partir de dados de Brasil (2006).

A Figura 2 ilustra o desempenho favorável dos produtos agrícolas, ao lado de uma evolução excepcional dos produtos animais do lado das exportações. Os saldos favoráveis têm contribuído a queda nas importações de produtos animais.

Figura 2. Saldo agropecuário

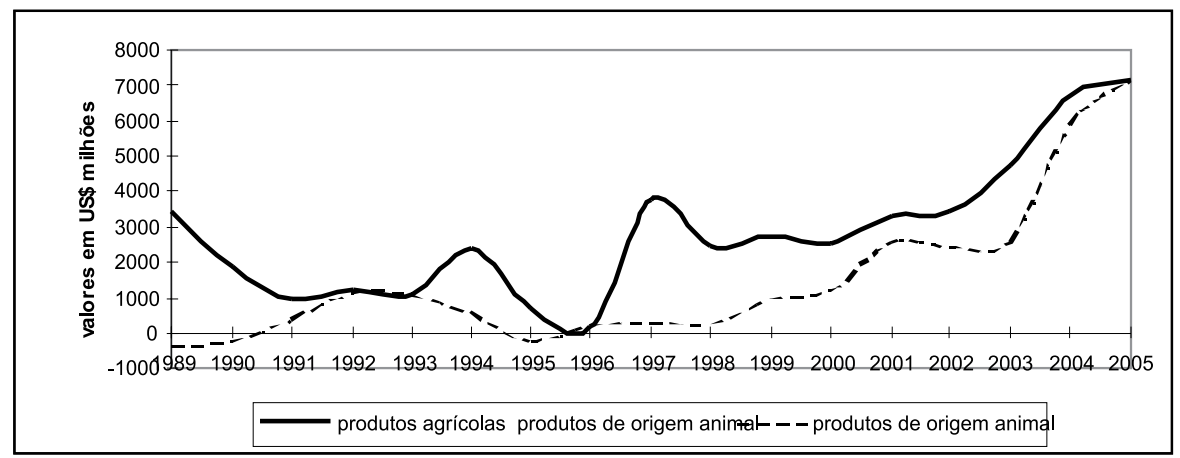

Fonte: Elaborado a partir de dados de Brasil (2006).

Nas Figuras 3 e 4, são apresentados detalhes por grupos específicos de produtos agroindustriais. Nota-se a grande importância desempenhada pela indústria de alimentos no saldo comercial do agronegócio brasileiro como um todo. Com saldos em torno de 6 a 7 bilhões de dólares por ano, esse segmento vem sustentando de forma consistente 
a participação brasileira nos segmentos de maior valor agregado no mercado internacional.

Figura 3. Saldo agroindústria (1)

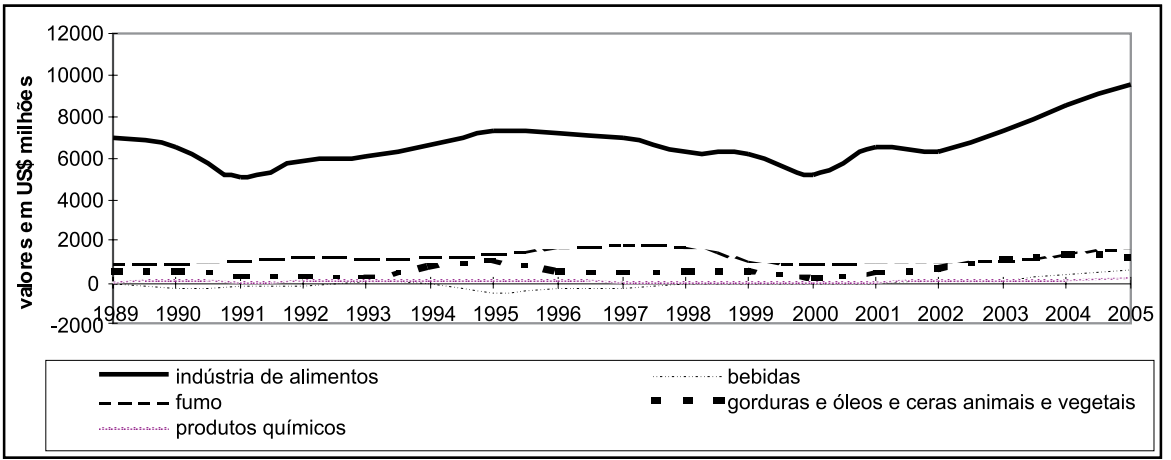

Fonte: Elaborado a partir de dados de Brasil (2006).

A importância desempenhada pelo setor de fabricação de calçados e a grande ascensão do setor de madeira e mobiliário podem ser observadas na Figura 4.

Figura 4. Saldo agroindústria (2)

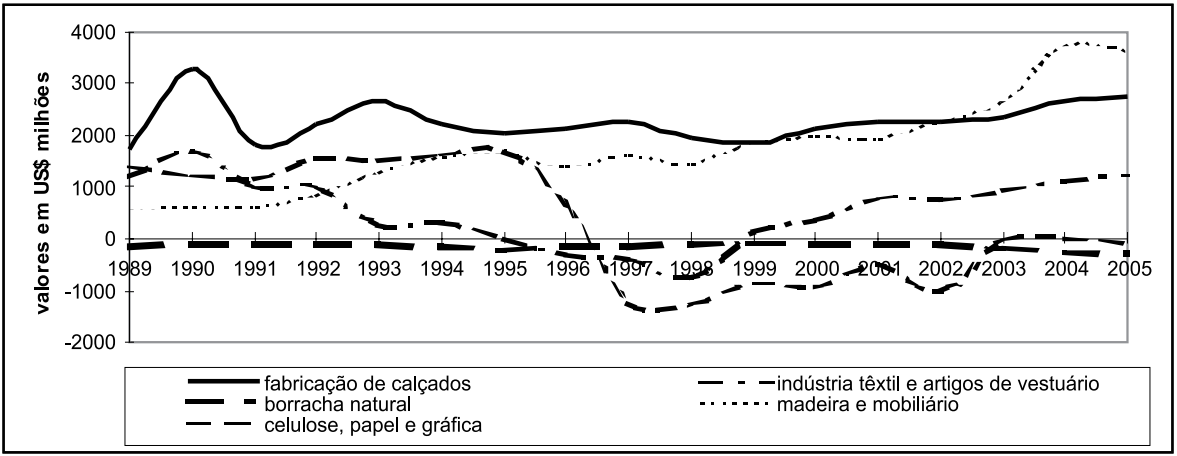

Fonte: Elaborado a partir de dados de Brasil (2006).

Finalmente, pela Figura 5, que reúne os sub-grupos considerados nas Figuras de 1 a 4, pode-se notar que, em conseqüência do aumento das exportações do agronegócio nos últimos anos e queda das importações, particularmente, após as desvalorizações cambiais de 1999 e 
subseqüentes, o saldo total apresentou crescimento considerável. Em 2005, um saldo de 32 bilhões de dólares foi alcançado.

Figura 5. Saldo total do agronegócio

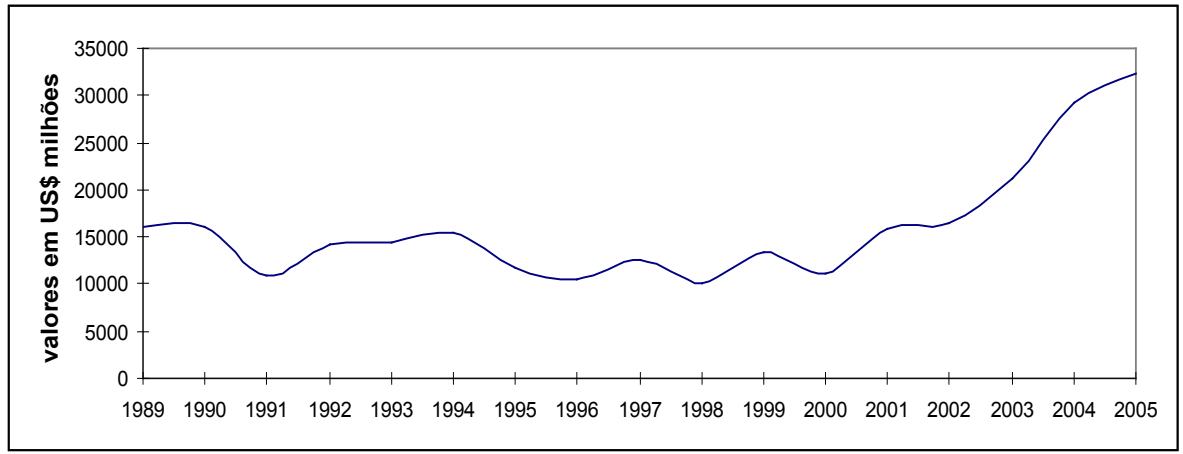

Fonte: Elaborado a partir de dados de Brasil (2006).

Através dos gráficos acima, pôde ser observado que o Brasil depende, de forma crescente, da importação de fertilizantes. A tabela abaixo mostra, em média, as importações de 2001 a 2005 dos principais fertilizantes importados. Pode-se observar que a maior parte deles são fertilizantes potássicos.

Tabela 1. Os principais fertilizantes importados pelo Brasil (2001-2005)

\begin{tabular}{lllc}
\hline NCM & Descrição & Valores em US\$ FOB & Participações (\%) \\
\hline \multirow{2}{*}{31042090} & Outros cloretos de potássio & 236.826 .348 & 51,21 \\
\multirow{2}{*}{31021010} & Uréia com teor de $\mathrm{N}>45 \%$ em peso & 121.859 .859 & 15,88 \\
\hline
\end{tabular}

Fonte: Elaborado a partir de dados de Brasil (2006) ${ }^{3}$

Outro grupo bastante representativo para o agronegócio é o que inclui os produtos animais. Dentro deste grupo, merecem destaque as carnes de frango ("pedaços e miudezas, comestíveis de galos/galinhas congelados”) e bovina (“carnes desossadas de bovino, congeladas”).

${ }^{3}$ A forma de cálculo dessas participações pode ser encontrada no item "fonte de dados". 
Tabela 2. Os principais produtos de origem animal exportados pelo Brasil (2001-2005)

\begin{tabular}{llll}
\hline NCM & Descrição & Valores em US\$ FOB & Participações (\%) \\
\hline \multirow{2}{*}{2071400} & $\begin{array}{l}\text { Pedaços e miudezas, comestíveis } \\
\text { de galos/galinhas, congelados }\end{array}$ & 205.848 .856 & 29,78 \\
& Carnes desossadas de bovino, & & \\
\multirow{2}{*}{2023000} & congelados & 150.592 .926 & 21,79 \\
2032900 & Outras carnes de suíno, congeladas & 71.329 .624 & 10,32 \\
\hline
\end{tabular}

Fonte: Elaborado a partir de dados de Brasil (2006) .

No caso dos produtos agrícolas, pode-se observar que a soja em grão ("outros grãos de soja, mesmo triturados") corresponde à mais da metade do total exportado no período de 2001 a 2005, em média. Em seguida, nota-se a grande importância desempenhada pelo café ("café não torrado, não descafeinado, em grão”).

Tabela 3. Os principais produtos agrícolas exportados pelo Brasil (2001-2005)

\begin{tabular}{llll}
\hline NCM & Descrição & Valores em US\$ FOB & Participações (\%) \\
\hline \multirow{2}{*}{12010090} & $\begin{array}{l}\text { Outros grãos de soja, mesmo } \\
\text { triturados }\end{array}$ & 638.948 .747 & 54,39 \\
& Café não torrado, não descafeina- & & \\
9011110 & do, em grão & 245.254 .456 & 20,88 \\
\hline
\end{tabular}

Fonte: Elaborado a partir de dados de Brasil (2006) .

Entre os produtos agroindustriais, observa-se que a indústria de alimentos é a que mais contribui para os saldos superavitários do agronegócio. Os principais produtos exportados no período foram farelo de soja ("bagaços e outro resíduos sólidos, da extração de óleo de soja”), açúcar ("açúcar de cana, em bruto") e suco de laranja ("sucos de laranja, congelados, não fermentados”).

${ }^{4}$ A forma de cálculo dessas participações pode ser encontrada no item "fonte de dados". ${ }^{5}$ A forma de cálculo dessas participações pode ser encontrada no item "fonte de dados”. 
Tabela 4. Os principais produtos da indústria de alimentos exportados pelo Brasil (2001-2005)

\begin{tabular}{llll}
\hline NCM & Descrição & Valores em US\$ FOB & Participações (\%) \\
\hline & Bagaços e outros resíduos & & \\
& sólidos, da extração de óleo & & \\
23040090 & de soja & 399.913 .709 & 34,947 \\
17011100 & Açúcar de cana, em bruto & 238.625 .795 & 20,853 \\
\hline
\end{tabular}

Fonte: Elaborado a partir de dados de Brasil (2006) ${ }^{3}$.

\subsection{Objetivos}

Este artigo objetiva analisar a balança comercial do agronegócio, desdobrando-a em seus componentes considerados mais representativos dos lados dos produtos e insumos para o período de 1989 a 2005, de modo a permitir uma análise mais integrada dos efeitos de políticas econômicas que afetam de forma diversa os grupos do setor. Tentarse-á antecipar a possibilidade de ocorrer conflitos entre a geração dos superávits do setor e a manutenção do custo de vida e da inflação sob controle.

Alguns grupos que compõem o saldo comercial do agronegócio brasileiro serão analisados: fertilizantes, produtos agrícolas, produtos de origem animal e indústria de alimentos.

Deste modo, espera-se obter uma visão mais detalhada dos segmentos do agronegócio, no tocante ao relacionamento externo, sem se perder, porém, em minúcias específicas a cada tipo de produto. A proposta é traçar um retrato geral de cada grupo, que evidencie seu comportamento durante o período de análise e que sirva de instrumental para analisar de forma mais adequada a contribuição de cada um para o saldo comercial.

Serão analisadas as exportações dos produtos agrícolas, produtos de origem animal e indústria de alimentos já que, para estes, os aumentos nas exportações são os maiores determinantes para os crescentes saldos observados. No caso dos fertilizantes, a proposta é focar a análise nas importações, cujo crescimento tem-se mostrado muito significativo.

Para tanto, serão elaborados modelos de importação e exportação 
que retratem o comportamento dessas variáveis frente aos seus determinantes, tais como: renda interna, taxa de câmbio, além das variações de preços internos (representando o comportamento do mercado interno), externos (representando o comportamento do mercado externo) e da produtividade observadas no período. Neste último ponto, espera-se encontrar uma medida adequada da produtividade que não fique prejudicada pela evolução dos preços - é comum, no agronegócio, os preços caírem em decorrência da elevação da produtividade, efeito que precisa ser eliminado para computar a evolução da produtividade.

\section{Metodologia}

\subsection{O conceito de agronegócio e a balança comercial do setor}

O estudo de Tomich et al. (2001) constitui o alicerce para a construção da balança comercial do agronegócio. Isso se deve à forma de agregação dos setores. Por meio dessa estrutura, será possível analisar os principais grupos de produtos do agronegócio brasileiro e destacar suas importâncias.

As mercadorias consideradas neste projeto podem ser obtidas com os autores deste estudo. Buscou-se considerar os setores classificados pela Escola Superior de Agricultura Luiz de Queiroz (Esalq), da Universidade de São Paulo (USP), pela Confederação da Agricultura e Pecuária do Brasil (CNA) e pela Associação Brasileira de Agribusiness (Abag), visto que estas já possuem um maior rigor proporcionado pela análise da matriz insumo-produto. Para os itens correspondentes a fatores de produção, a classificação do Instituto de Economia Agrícola (IEA) auxiliou no processo de classificação devido à necessidade de respaldo de um conhecimento técnico mais aprofundado e adequado. Além disso, a classificação do Ministério da Agricultura, Pecuária e Abastecimento (Mapa) também forneceu grande auxílio no caso, principalmente, das mercadorias incluídas em Agroindústria (2). Informações foram obtidas em Barros, Furtuoso e Guilhoto (2002), da Esalq/USP, Nunes e Contini (2000), da Abag, e Vicente et al. (2002), do IEA.

Portanto, a balança comercial do agronegócio, elaborada segundo 
os critérios anteriores, organizar-se-á da seguinte forma:

I) Fatores de produção: fertilizantes, máquinas (incluindo tratores) e defensivos.

II) Agropecuária: produtos agrícolas e produtos de origem animal.

III) Agroindustriais.

IIIa) Agroindústria (1): indústria de alimentos, bebidas, fumo, gorduras e óleos e ceras animais e vegetais, produtos químicos.

IIIb) Agroindústria (2): fabricação de calçados, indústria têxtil e artigos de vestuário, borracha natural, madeira e mobiliário e celulose, papel e gráfica.

\subsection{Modelos básicos para as importações e exportações}

\subsubsection{Modelos empíricos setoriais}

\subsubsection{Modelo de exportação}

Um mesmo modelo geral comum será formulado para os três grupos de produtos de exportação. Um modelo específico será estipulado a seguir para o caso das importações de fertilizantes. Pressupõe-se que o Brasil seja, em todos os casos, um tomador de preços.

O modelo aqui apresentado utiliza as idéias básicas desenvolvido por Blanchard e Quah (1989), e adaptadas ao setor agrícola por Alves (2006) e Spolador (2006). Neste caso, pretende-se verificar em que medida o desempenho da exportação do agronegócio e seus setores individuais pode ser atribuído a choques provenientes de fatores ligados à demanda interna (como a renda), à atratividade do mercado externo (como o câmbio e os preços internacionais) e à renda externa, além dos fatores relacionados à oferta (como a produtividade). Ao contrário do modelo de Blanchard e Quah (1989), não será imposta restrição de longo prazo para captar os efeitos permanentes e temporários. Sem perda de generalidade, supõe-se elasticidades unitárias nas várias relações envolvidas.

Apresenta-se, primeiramente, o modelo para o segmento de produtos agrícolas. O mesmo modelo se aplica para produtos animais e alimentos processados; nesses dois casos, porém, não é incluída a variáv- 
el produtividade pela dificuldade de medida dessa variável. No caso da pecuária, a dificuldade deve-se à falta de uma medida adequada da produção de produtos animais. No caso de produtos processados, faria mais sentido medi-la em relação à mão-de-obra. Novamente, falta uma série consistente de dados para tal.

A demanda interna pelo produto do agronegócio (em logaritmos) é dada por:

$$
y_{t}^{d}=m_{t}-p_{t}
$$

no qual: y é a quantidade; $\mathrm{m}$ a renda nacional real e $\mathrm{p}$ é o preço doméstico do produto.

O produto (em logaritmos) é dado ainda por:

$$
y_{t}^{s}=\eta_{t}+\theta_{t}
$$

ou

$$
y_{t}^{s}=E\left(p_{t}\right)+\theta_{t}
$$

em que $\theta$ é a produtividade da terra e $\eta$ a área colhida (que depende da expectativa de preço).

A exportação (x) é dada pelo excedente de mercado interno, identificado como:

$$
x_{t}=y_{t}^{s}-y_{t}^{d}
$$

Outros componentes do modelo são:

a) choques de renda interna $\left(e^{d}\right)$ :

$$
m_{t}=m_{t-1}+e_{t}^{d}
$$

b) choques de produtividade, que afetam a oferta $\left(\mathrm{e}^{\mathrm{s}}\right)$ :

$$
\theta_{t}=\theta_{t-1}+e_{t}^{s}
$$


c) choques de preço interno (ep):

O preço interno é representado de forma estilizada como sendo ligado ao preço externo (expresso em reais) por uma margem de exportação. Supõe-se que até produtos que não sejam transacionados externamente sejam influenciados pelos preços externos daqueles que o são. Efeitos-substituição na produção se encarregariam dessa relação. Seja então :

$$
p_{t}=\alpha+p_{t}^{x}+e_{t}^{p}
$$

no qual $\alpha$ é o log da margem de exportação e $p^{x}$ é o preço externo transformado em reais. Este valor mede a atratividade da exportação, sendo o produto do preço externo em dólares pela taxa de câmbio (Reais/dólar).

d) choque de preço externo $\left(e_{t}^{p x}\right)$

$$
p_{t}^{x}=m_{t}^{x}+e_{t}^{p x}
$$

no qual $\mathrm{m}^{\mathrm{x}}$ é a renda externa, dada por

$$
m_{t}^{x}=m_{t-1}^{x}+e_{t}^{m x}
$$

Os choques $e^{s}, e^{d}, e_{t}^{p}{ }_{t}, e^{p x}{ }_{t}$ e $e^{m x}{ }_{t}$ têm média zero, são não-correlacionados e não apresentam autocorrelações.

Retomando a expressão para exportação:

$$
\begin{aligned}
& x_{t}=y_{t}^{s}-y_{t}^{d} \\
& x_{t}=\left(\eta_{t}+\theta_{t}\right)-\left(m_{t}-p_{t}\right) \\
& x_{t}=\left[E\left(p_{t}\right)+\left(\theta_{t-1}+e_{t}^{s}\right)\right]-\left[\left(m_{t-1}+e_{t}^{d}\right)-\left(\alpha+p_{t}^{x}+e_{t}^{p}\right)\right] \\
& x_{t}=\left[\left(\alpha+m_{t-1}^{x}\right)+\left(\theta_{t-1}+e_{t}^{s}\right)\right]-\left[\left(m_{t-1}+e_{d}^{t}\right)-\left(\alpha+p_{t}^{x}+e_{t}^{p}\right)\right]
\end{aligned}
$$

e variação em x (ou taxa de crescimento da exportação) será: 


$$
\Delta x_{t}=2 e_{t-1}^{m x}+e_{t}^{s}-e_{t}^{d}+\left(e_{t}^{p x}-e_{t-1}^{p x}\right)+\left(e_{t}^{p}-e_{t-1}^{p}\right)
$$

Assim, observa-se que:

a) aumentos na renda externa elevam as exportações após uma defasagem pelo efeito que a elevação do preço externo tem no preço interno que, por sua vez, eleva a produção e reduz a demanda;

b) aumentos na produtividade elevam as exportações porque deslocam a oferta doméstica para a direita;

c) aumentos na demanda interna reduzem as exportações;

d) aumentos no preço externo elevam as exportações (ao reduzirem a demanda interna) quando ocorrem e a reduzem no momento seguinte;

e) aumentos no preço interno elevam as exportações (ao reduzirem a demanda interna) quando ocorrem e a reduzem no momento seguinte.

\subsubsection{Modelo de importação}

No caso do modelo para importação de fertilizante, também se considera a expressão geral

$$
x_{t}=z_{t}^{d}-z_{t}^{s}
$$

no qual $z_{t}^{s}$ e $z_{t}^{d}$ são a oferta e demanda domésticas de fertilizantes. A demanda é dada por

$$
z_{t}^{d}=E\left(p_{t}\right)-\beta r_{t}
$$

sendo p o preço interno dos produtos agrícolas e r o preço interno de fertilizantes. A oferta é dada por

$$
z_{t}^{s}=\delta r_{t}
$$

Os componentes do modelo são:

a) preço interno dos fertilizantes:

$$
r_{t}=\gamma+r_{t}^{x}+e_{t}^{r}
$$


b) o preço externo dos fertilizantes convertido em reais, $\mathrm{r}^{\mathrm{x}}$ :

$$
r_{t}^{x}=r_{t-1}^{x}+e_{t}^{r x}
$$

c) preço interno dos produtos agrícolas:

$$
p_{t}=\alpha+p_{t}^{x}+e_{t}^{p}
$$

d) preço externo dos produtos agrícolas:

$$
p_{t}^{x}=p_{t-1}^{x}+e_{t}^{p x}
$$

Logo:

$$
\begin{aligned}
& x_{t}=E\left(p_{t}\right)-\beta r_{t}-\delta r_{t} \\
& x_{t}=E\left(p_{t}\right)-(\delta+\beta)\left(\gamma+r_{t}^{x}+e_{t}^{r}\right) \\
& x_{t}=\alpha+p_{t-1}^{x}-(\delta+\beta)\left[\gamma+\left(r_{t-1}^{x}+e_{t}^{r x}+e_{t}^{r}\right)\right.
\end{aligned}
$$

e variação em x (ou taxa de crescimento da importação):

$$
\Delta x_{t}=e_{t-1}^{p x}-(\delta+\beta)\left[e_{t}^{r x}+\left(e_{t}^{r}-e_{t-1}^{r}\right)\right]
$$

À luz desses resultados tem-se as seguintes hipóteses:

a) aumentos no preço externo do produto $\left(e_{t}^{p x}>0\right)$ elevarão as importações de fertilizantes no período seguinte;

b) aumentos no preço externo de fertilizante $\left(e_{t}^{r x}>0\right)$ reduzirão as importações de fertilizantes;

d) aumentos no preço doméstico de fertilizante $\left(e_{t}^{r}>0\right)$ reduzirão as importações de fertilizantes no momento corrente e elevarão no momento seguinte, desaparecendo seu efeito. 


\subsection{Procedimentos metodológicos}

A técnica econométrica empregada será o método de Análise de Auto-Regressões Vetoriais (Vector Autoregression Analysis - VAR), por suas características de: (a) permitir considerar, em princípio, todas as variáveis como endógenas; (b) considerar os choques causais com evolução típica e não-constantes como se dá nas análises "coeteris paribus"; (c) explicitamente considerar os impactos de choques não-antecipados; (d) fornecer uma previsão dinâmica dos efeitos, indicando os impactos acumulados ao longo do tempo. O modelo de vetores auto-regressivos foi proposto por Sims (1980), que defendeu a premissa de que todas as variáveis devem ser tratadas de forma simultânea e simétrica. Detalhes sobre a metodologia VAR estão descritos em Enders (1995).

Para estimar os testes de raiz unitária utilizar-se-á o software Regression Analysis of Time Series (Rats) versão 4.0 e para os testes de cointegração e para a especificação do modelo VAR, o Rats versão 5.0.

\subsection{Testes econométricos: os testes de raiz unitária e co-integração}

Foram utilizados os critérios de Akaike (AIC) e Schwarz (SC) para determinar o número de defasagens (ordem do processo auto-regressivo) a ser adotado no testes de raiz unitária. A partir da sinalização obtida pelos testes de AIC e SC, a definição do número de defasagens a ser incluído em cada modelo foi feita de forma seqüencial, iniciando-se com o número indicado e eliminando-se os termos cujos coeficientes apresentaram-se não significativos. Após determinado o número de defasagens para cada variável, foi realizado o teste de Dickey-Fuller Aumentado (ADF). O procedimento adotado foi baseado em Enders (1995), incluindo os testes $\phi_{3}$ e $\phi_{1}$, sendo que o primeiro testa a presença de tendência e constante simultaneamente e o segundo, a presença de constante, sem tendência. Verificou-se que todas as séries consideradas nos diferentes modelos são integradas de ordem I(1), e realizou-se o teste de cointegração de Johansen (1988) para analisar as relações de longo prazo entre as variáveis.

Pelos testes $\lambda_{\max }$ e $\lambda_{\text {trace }}$ foi especificado o número de vetores para o modelo VAR com Termo de Correção de Erro para cada grupo de produtos. Os resultados de cada um dos testes podem ser obtidos com os autores. 


\subsection{Fonte de dados}

\subsubsection{Dados de exportação e importação}

Em relação aos dados trimestrais de exportação e importação para o período de 1989 a 2005, todos foram obtidos por meio do Sistema Aliceweb (Brasil, 2006). Os valores foram deflacionados pelo Índice de Preços ao Consumidor dos EUA, do Instituto em Economia Aplicada (Ipea), tendo como base o ano de 2004.

\subsubsection{Renda externa}

A exemplo de um grande número de trabalhos, o valor das importações mundiais foi utilizado como proxy da renda externa. A série, em bilhões de dólares, é divulgada pelo Ipea e foi deflacionada pelo IPCEUA, base 2004 .

\subsubsection{Preços externos}

2.5.3.1. Produtos agrícolas, produtos de origem animal e indústria de alimentos

A partir das mercadorias consideradas neste trabalho, foram selecionados os produtos mais representativos.

1) Para alguns grupos, foram analisados os capítulos aos quais se referiam de forma a encontrar a soma dos produtos que representaram mais do que $70 \%$ para cada capítulo no ano de 2004 . Foi o caso dos produtos agrícolas; produtos de origem animal; bebidas; fumo; gorduras; óleos e ceras animais e vegetais e celulose, papel e gráfica. Em alguns casos, foram considerados os capítulos em sua totalidade por nenhum item sozinho ou no mínimo dez representarem mais do que $70 \%$ de cada capítulo considerado no grupo.

2) Outros grupos como fertilizantes, defensivos, máquinas e implementos, incluindo tratores, produtos químicos e borracha natural, são for- 
mados por mercadorias individuais, não por capítulos inteiros como nos casos anteriores. Mercadorias com valores inferiores a US $\$ \mathbf{5 . 0 0 0 . 0 0 0 , 0 0}$ foram excluídas.

3) Outros grupos, como fabricação de calçados, indústria têxtil e artigos para vestuário e madeira e mobiliário somam capítulos completos e mercadorias individuais, para os quais foram adotados os critérios acima simultaneamente.

\section{a) Produtos agrícolas}

A partir disso, em primeiro lugar, calculou-se, para o período de 2000 a 2004, a participação relativa dos produtos agrícolas em relação a todos os produtos considerados. Em seguida, foi calculado a média dessas participações relativas.

Foram divididos os valores totais pelas quantidades totais de produtos agrícolas para cada trimestre considerado, encontrando-se, assim, seus respectivos valores unitários. O terceiro trimestre do ano de 2000 foi considerado o período base. Assim, cada valor unitário foi ponderado por essa base, transformando-se em um índice de valor unitário relativo.

Após esses dois cálculos, o Índice de Preços Externos Agrícolas foi calculado multiplicando-se a média das participações relativas pelo índice de valor unitário relativo.

b) Produtos de origem animal

Assim como no caso anterior, em primeiro lugar, foi calculado, para o período de 2000 a 2004, a participação relativa dos produtos de origem animal em relação a todos os produtos considerados. Em seguida, calculou-se a média dessas participações relativas. Ao mesmo tempo, foram divididos os valores totais pelas quantidades totais de produtos de origem animal para cada trimestre considerado, encontrando-se, dessa forma, seus respectivos valores unitários. O terceiro trimestre do ano de 2000 foi considerado o período base. Assim, cada valor unitário foi ponderado por essa base, transformando-se em um índice de valor unitário relativo.

Após esses dois cálculos, o Índice de Preços Externos Animais foi 
calculado, multiplicando-se a média das participações relativas pelo índice de valor unitário relativo.

c) Indústria de alimentos

O mesmo procedimento descrito nos casos anteriores foi utilizado para a indústria de alimentos.

\subsubsection{Fertilizantes}

Foram considerados 14 tipos de fertilizantes, selecionados, por juntos, representarem $84 \%$ do valor importado pelo setor.

A partir disso, em primeiro lugar, calculou-se, para o período 2001 a 2005, a participação relativa de cada fertilizante em relação a todos os produtos considerados. Em seguida, calculou-se a média dessas participações relativas.

Além disso, foram divididos os valores pelas quantidades para cada fertilizante em cada trimestre considerado, encontrando-se, assim, seus respectivos valores unitários. O terceiro trimestre do ano de 2000 foi considerado o período base. Assim, cada valor unitário foi ponderado por essa base, transformando-se em um índice de valor unitário relativo.

Após esses dois cálculos, o Índice de Preços Externos Fertilizantes foi calculado multiplicando-se a média das participações relativas pelo índice de valor unitário relativo.

\subsubsection{Taxa de câmbio}

2.5.4.1. Produtos agrícolas, produtos de origem animal e indústria de alimentos

Foi utilizado o Índice da Taxa Efetiva de Câmbio do Agronegócio Brasileiro calculado pelo Cepea/Esalq-USP, com base nos pesos de cada país importador de produtos desse setor. 


\subsubsection{Fertilizantes}

Neste caso, foi utilizada a Taxa de Câmbio Efetiva Real divulgada pelo Ipea, que se refere à economia brasileira como um todo. Suas ponderações referem-se às correntes de comércio entre o Brasil e seus parceiros comerciais. O índice da taxa efetiva para o agronegócio usado para as mercadorias aplica-se, por construção, apenas para as exportações.

\subsubsection{Atratividade}

Os índices de atratividade foram calculados, multiplicando-se os preços externos de cada grupo de produtos pelas respectivas taxas de câmbio. No caso das exportações, os preços internos em dólares são multiplicados pela taxa efetiva do agronegócio. Já para as importações, os preços externos são multiplicados pela taxa efetiva calculada pelo Ipea.

\subsubsection{Renda interna}

Foi utilizado o PIB trimestral divulgado pela Fundação Getúlio Vargas (FGV).

\subsubsection{Preços internos}

a) Produtos agrícolas

Considerou-se uma cesta formada pelos seguintes produtos: algodão, arroz, cacau, café, cana, feijão, laranja, mandioca, milho, soja e trigo. Todos os preços, com periodicidade trimestral, foram coletados na FGV, deflacionados pelo IGP-DI (base 2004) e uniformizados em R \$/ toneladas.

Primeiro, foram calculadas as participações de cada mercadoria no valor total da produção agrícola a preço constante ${ }^{6}$ : (a) calculou-se a

\footnotetext{
${ }^{6}$ Notar a importante diferença entre valor da produção a preço constante e valor da produção a preços reais. No primeiro caso, as produções individuais são ponderadas pelos preços reais médio do período total de análise (total de trimestres considerados) e, no segundo, as produções individuais são ponderadas pelos preços reais de cada trimestre.
} 
média desses preços reais de cada mercadoria para o período de análise; (b) multiplicou-se, então, a média de preço real de cada mercadoria pela sua produção anual, dada pela Food and Agriculture Organization (FAO), em toneladas; (c) para obter o valor total da produção agrícola a preço constante, somam-se esses produtos; (d) a participação de cada mercadoria no valor da produção resulta da divisão do valor de cada uma pelo valor total da produção a preço constante.

Posteriormente, os preços trimestrais de cada produto foram multiplicados por sua participação relativa na produção a preços fixos, chegando-se ao Preço Lavouras - Produção a Preços Fixos.

b) Produtos de origem animal

Para os produtos de origem animal, foi utilizado o Índice de Preços Recebidos pelos Produtores - Produtos Animais (IPR, Produtos Animais), da FGV.

Todos os preços foram coletados trimestralmente e deflacionados pelo Índice Geral de Preços (IGP).

c) Indústria de alimentos

Para a indústria de alimentos, utilizou-se o Índice de Preços por Atacado Oferta Global (IPA-OG, Produtos Alimentares - Total) da FGV. Todos os preços foram coletados trimestralmente e deflacionados pelo IGP.

d) Fertilizantes

Já para os fertilizantes, foi utilizado o Índice de Preços Pagos pelos Produtores (IPP- Fertilizantes), da FGV. Todos os preços foram coletados trimestralmente e deflacionados pelo IGP.

\subsubsection{Produtividade}

Utilizaram-se as mesmas séries de dados citadas acima, além de dados de área encontrados na FAO.

Para cada ano, a produção física de cada mercadoria foi multiplicada pelo seu preço real fixo para o período total de análise. Esses produtos foram, então, somados para obter o valor total da produção 
a preço fixo. Esse valor é, a seguir, dividido pela soma das áreas de cada produto. Encontrou-se, assim, a série anual de produtividade. Por serem as demais séries trimestrais e por ser a série de produtividade necessariamente anual, adotou-se o procedimento de repetir o valor da produtividade para os quatro trimestres do ano.

\section{Resultados e Discussão}

\subsection{Produtos agrícolas}

Por meio da decomposição da variância dos erros de previsão, o modelo VAR permite avaliar o poder explanatório de cada variável sobre as demais. Por exemplo, observou-se que a maior parte da variação nas exportações é explicada pela atratividade, em média $62,4 \%$, sendo que no primeiro trimestre esse porcentual chega a $73,8 \%$.

Tabela 5. Decomposição histórica da variância do erro de previsão devido aos choques (\%) para a exportação de produtos agrícolas

\begin{tabular}{cccccccc}
\hline Trimestre & $\begin{array}{c}\text { Desvio } \\
\text { padrão }\end{array}$ & $\begin{array}{c}\text { Expor } \\
\text { tações }\end{array}$ & $\begin{array}{c}\text { Atrati } \\
\text { vidade }\end{array}$ & $\begin{array}{c}\text { Renda } \\
\text { externa }\end{array}$ & $\begin{array}{c}\text { Produti } \\
\text { vidade }\end{array}$ & $\begin{array}{c}\text { Preço } \\
\text { interno }\end{array}$ & $\begin{array}{c}\text { Renda } \\
\text { interna }\end{array}$ \\
\hline 1 & 0.200 & 14.849 & 73.880 & 0.356 & 5.963 & 4.946 & 0.006 \\
2 & 0.234 & 19.555 & 63.657 & 0.481 & 4.594 & 7.533 & 4.179 \\
3 & 0.240 & 18.981 & 62.626 & 1.780 & 4.638 & 7.516 & 4.460 \\
4 & 0.242 & 18.682 & 61.881 & 3.112 & 4.561 & 7.381 & 4.384 \\
\hline
\end{tabular}

Fonte: Dados da pesquisa.

Pela função impulso-resposta acumulada, verificou-se que a atratividade aumenta sensivelmente às exportações, principalmente no primeiro trimestre. Esse efeito estabiliza-se em torno de 2,0, ou seja, se atratividade aumentar $10 \%$, as exportações aumentariam $20 \%$. Recorda-se que, por construção, tal aumento na atratividade pode decorrer de uma combinação de variações na taxa de câmbio e no preço em dólares que sobe $10 \%$. 
Figura 6. Função de impulso-resposta acumulada da exportação de produtos agrícolas a impulso de cada variável

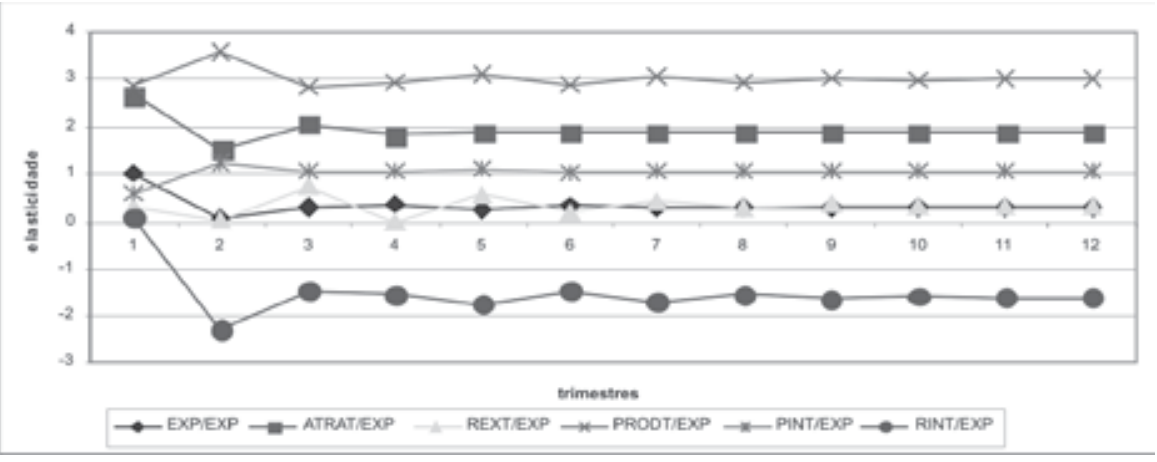

Fonte: Dados da pesquisa.

Da mesma maneira, a renda externa $(0,3 \%$ no primeiro trimestre, convergindo em $0,33 \%)$, a produtividade $(2,88 \%$ a $3 \%)$ e os preços internos $(0,61 \%$ a $1,07 \%)$ impulsionam as exportações. Além disso, um crescimento de $1 \%$ no PIB doméstico tem impactos expressivos (chegando a $-1,7 \%$ ) de contenção das exportações dos produtos agrícolas. Embora estes efeitos não tenham apresentado poder relevante de explicação do erros de previsão, eles devem ser tomados em conta pelo impacto potencial que podem ter - uma queda expressiva pode ocorrer no ritmo exportador do agronegócio face a uma retomada do crescimento econômico brasileiro. Neste caso, por exemplo, cada ponto percentual de crescimento do PIB teria de ser compensado por semelhante desvalorização cambial real para conter a demanda interna e manter as exportações. Salienta-se, entretanto, que a expansão das exportações do agronegócio tem-se dado sob incremento importante da produtividade, que pode ser o elemento capaz de compatibilizar o crescimento das exportações e o atendimento do mercado interno sem pressões inflacionárias relevantes.

\subsection{Indústria de alimentos}

Pode-se observar pela Tabela 6, que a atratividade é responsável pela maior parte da variância das exportações da indústria de alimen- 
tos, com aproximadamente $32,7 \%$. Logo em seguida, a própria variável, com $28,5 \%$, o preço interno, com $20,8 \%$ e a renda interna, com $17,9 \%$.

Tabela 6. Decomposição histórica da variância do erro de previsão devido aos choques (\%) para as exportações da indústria de alimentos

\begin{tabular}{cccccc}
\hline Trimestre & $\begin{array}{c}\text { Desvio } \\
\text { padrão }\end{array}$ & Exportações & Atratividade & $\begin{array}{c}\text { Renda in- } \\
\text { terna }\end{array}$ & $\begin{array}{c}\text { Preço } \\
\text { interno }\end{array}$ \\
\hline 1 & 0.151 & 28.558 & 28.928 & 21.696 & 20.818 \\
2 & 0.169 & 28.482 & 33.465 & 17.571 & 20.483 \\
3 & 0.171 & 28.605 & 33.123 & 17.639 & 20.633 \\
4 & 0.172 & 28.571 & 33.003 & 17.615 & 20.811 \\
\hline
\end{tabular}

Fonte: Dados da pesquisa.

Pela função impulso-resposta acumulada, verificou-se que a atratividade aumenta as exportações, principalmente no primeiro trimestre. Os preços internos também impulsionam as exportações, enfatizando o expressivo coeficiente encontrado na matriz de coeficientes de relações contemporâneas $(0,38)$. A resposta ao choque na renda interna, e apesar de ser a variável que menos explica a variância das exportações, esse valor chega a $17,9 \%$.

Figura 7. Função de impulso-resposta acumulada da exportação da indústria de alimentos a impulso de cada variável

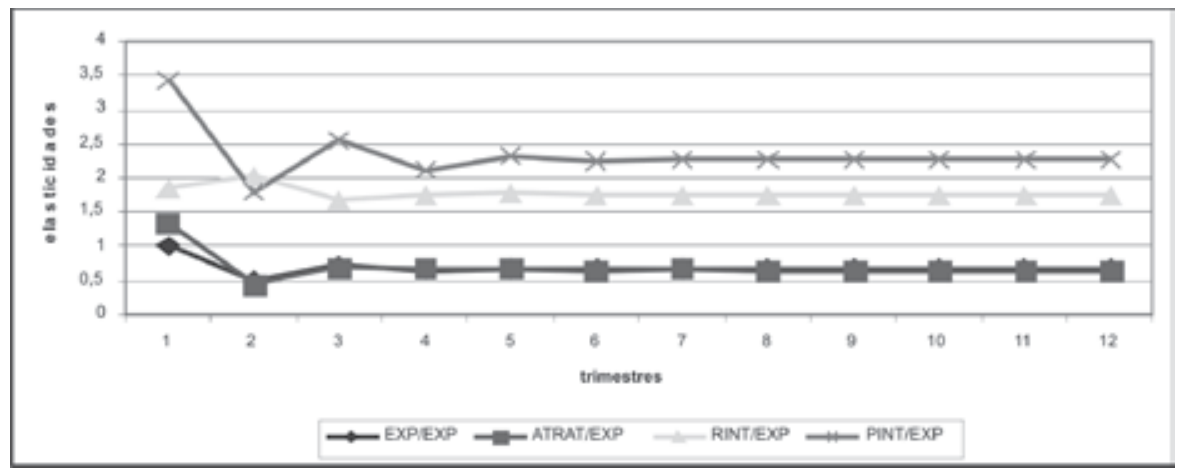

Fonte: Dados da pesquisa. 


\subsection{Produtos de origem animal}

Pela decomposição da variância dos erros de previsão, as exportações de produtos de origem animal são explicadas, 46,6\%, em média, por elas mesmas. Em seguida, pela atratividade com $24,5 \%$, pelo preço interno, com $11,3 \%$, pela renda externa, com $9,9 \%$ e pela renda interna, $\operatorname{com} 8,2 \%$.

Tabela 7. Decomposição histórica da variância do erro de previsão devido aos choques (\%) para a exportação de produtos de origem animal

\begin{tabular}{ccccccc}
\hline Trimestres & $\begin{array}{c}\text { Desvio } \\
\text { padrão }\end{array}$ & Exportações & Atratividade & $\begin{array}{c}\text { Renda } \\
\text { externa }\end{array}$ & $\begin{array}{c}\text { Preço } \\
\text { interno }\end{array}$ & $\begin{array}{c}\text { Renda } \\
\text { interna }\end{array}$ \\
\hline 1 & 0.177 & 56.132 & 23.950 & 8.423 & 11.432 & 0.063 \\
2 & 0.196 & 46.450 & 25.036 & 8.656 & 11.518 & 8.340 \\
3 & 0.198 & 45.838 & 24.669 & 9.951 & 11.328 & 8.214 \\
4 & 0.198 & 45.700 & 24.596 & 10.198 & 11.315 & 8.191 \\
\hline
\end{tabular}

Fonte: Dados da pesquisa.

Pela função impulso-resposta acumulada, observou-se os efeitos positivos da atratividade $(1,05 \%$ a $1,57 \%)$ e da renda externa $(1,38 \%$ a $1,12 \%$ ) sobre as exportações e os efeitos negativos do preço interno $(-0,93 \%$ a $-0,49 \%)$ e da renda interna $(0,16 \%$ a $-1,94 \%)$. Apenas para esse grupo de produtos o aumento dos preços internos contribuiu para a queda das exportações, sugerindo que o preço interno preço interno parece não se vincular fortemente ao preço externo e ao câmbio. 
Figura 8. Função de impulso-resposta acumulada da exportação a impulso de cada variável

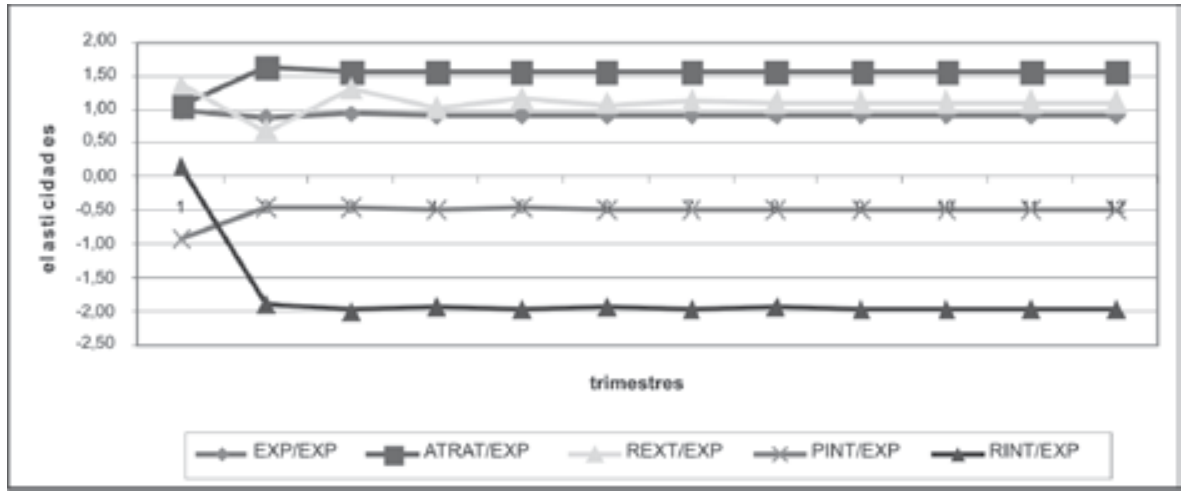

Fonte: Dados da pesquisa.

\subsection{Fertilizantes}

Pela decomposição da variância dos erros de previsão, as importações de fertilizantes são explicadas quase totalmente por elas mesmas. No primeiro período, chega a $87,7 \%$ e, na média, $78,8 \%$. Em seguida, a atratividade com $10 \%$ de poder explanatório e os preços internos dos produtos agrícolas com $8,1 \%$. Isso sugere que o Brasil tem uma dependência de fertilizantes importados, tendo de importá-lo, dentro de certos limites, quase que independentemente de considerações econômicas.

Tabela 8. Decomposição histórica da variância do erro de previsão devido aos choques (\%) para a importação de fertilizantes

\begin{tabular}{cccccc}
\hline Trimestres & $\begin{array}{c}\text { Desvio } \\
\text { padrão }\end{array}$ & Importação & Atratividade & $\begin{array}{c}\text { Preço } \\
\text { interno }\end{array}$ & $\begin{array}{c}\text { Preço } \\
\text { interno dos } \\
\text { agrícolas }\end{array}$ \\
\hline 1 & 0.437 & 87.735 & 4.810 & 0.013 & 7.441 \\
2 & 0.486 & 79.348 & 9.393 & 2.841 & 8.418 \\
3 & 0.492 & 78.304 & 10.384 & 3.087 & 8.225 \\
4 & 0.493 & 77.963 & 10.588 & 3.263 & 8.186 \\
\hline
\end{tabular}

Fonte: Dados da pesquisa. 
Pela função impulso-resposta acumulada, notam-se os papéis positivos desempenhados pela atratividade $(0,55 \%$ a $0,1 \%)$ e pelos preços internos dos produtos agrícolas $(1,37 \%$ a $0,54 \%)$ sobre as importações, principalmente no primeiro trimestre. Já os preços internos dos fertilizantes, ao contrário do esperado e observado na matriz de coeficientes contemporâneos, derrubariam as importações (0,09\% a -1,19\%). No entanto, como essa variável representa, em média, 3,2\% da variância das importações, o efeito pode ser considerado praticamente desprezível.

Figura 9. Função de impulso-resposta acumulada da importação de fertilizantes a impulso de cada variável

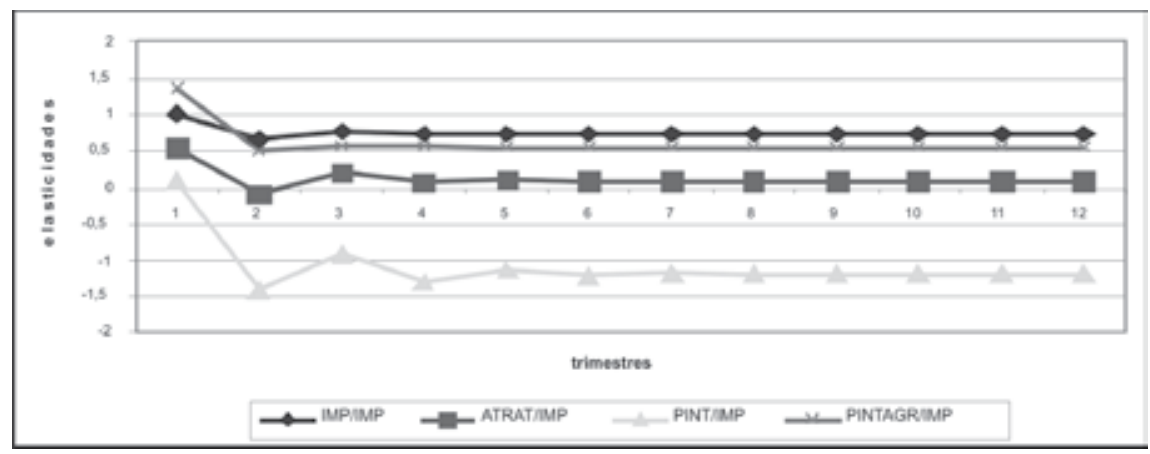

Fonte: Dados da pesquisa.

\section{Conclusões}

Foi proposta neste trabalho uma nova classificação de balança comercial do agronegócio brasileiro e feita uma análise dos fatores explicativos da formação de superávits comerciais pelo setor, considerando os componentes mais importantes do lado dos produtos exportados e dos insumos importados, para o período de 1989 a 2005. Assim foram selecionados: fertilizantes (representando o segmento de insumos importados), produtos agrícolas não-processados, produtos de origem animal não-processados e alimentos industrializados. Para tanto, foram elaborados modelos de importação e exportação, buscando retratar o comportamento dessas variáveis frente aos seus determinantes, tais como: renda interna, taxa de câmbio, além das variações de preços internos (representando o comportamento do mercado interno), externos (rep- 
resentando o comportamento do mercado externo) e da produtividade observadas no período. A técnica econométrica empregada foi o método de Análise de Auto-Regressões Vetoriais, por suas características de (a) permitir considerar, em princípio, todas as variáveis como endógenas; (b) considerar os choques causais com evolução típica e não-constantes como se dá nas análises "coeteris paribus"; (c) explicitamente considerar os impactos de choques não-antecipados; (d) fornecer uma previsão dinâmica dos efeitos, indicando a os impactos acumulados ao longo do tempo.

O principal fator que explica a exportação de produtos agrícolas é a sua atratividade - resultado do produto do preço externo em dólares pela taxa de câmbio em Reais por dólar. Como acontece normalmente com tais funções, as elasticidades são relativamente altas: 3,0 no primeiro trimestre (elasticidade igual a 3), convergindo para aproximadamente 1,9 após um ano. Da mesma maneira, a renda externa (elasticidade de $0,3)$, a produtividade $(2,88$ a 3$)$ e os preços internos $(0,61$ a 1,07$)$ agem positivamente sobre as exportações.

Pela análise da decomposição da variância, a maior parte da variação nas exportações de produtos agrícolas é explicada pela atratividade. Em seguida, vieram o preço interno, a produtividade, a renda interna e, por último, a renda externa.

Uma preocupação do trabalho era relacionada ao impacto que uma retomada do crescimento econômico teria sobre as exportações. Constatou-se que esse impacto pode ser potencialmente alto: um crescimento de $1 \%$ do PIB doméstico tem impactos expressivos, convergindo para $-1,7 \%$ de contenção das exportações dos produtos agrícolas. Embora estes efeitos não tenham apresentado poder relevante de explicação do erros de previsão, eles alertam para possíveis quedas no ritmo exportador do agronegócio face a uma retomada do crescimento econômico brasileiro. Entretanto, a expansão das exportações do agronegócio tem-se dado sob incremento importante da produtividade, que pode ser o elemento capaz de compatibilizar o crescimento das exportações e o atendimento do mercado interno sem pressões inflacionárias relevantes.

No caso dos produtos da indústria de alimentos, pôde-se notar, por exemplo, que um aumento de $1 \%$ atratividade aumenta as exportações entre $1,34 \%$ a $0,66 \%$. Pela decomposição da variância dos erros de 
previsão, observou-se que a maior parte da variação nas exportações é explicada pela atratividade, o que ressalta essa importância. Os preços internos também impulsionam as exportações $(3,42$ a 2,27). Pôde-se observar, também, que as exportações derrubam a atratividade $(-0,74$ a -0,76). Já a atratividade aumenta os preços internos $(0,25$ a 0,37$)$. Pela decomposição da variância dos erros de previsão, pôde-se observar que a atratividade é responsável pela maior parte da variância das exportações da indústria de alimentos. Logo em seguida, vêm a própria variável, o preço interno e a renda interna.

Para os produtos de origem animal não-processados observaramse os efeitos positivos da atratividade $(1,05$ a 1,57$)$ e da renda externa $(1,38$ a 1,12$)$ sobre as exportações e os efeitos negativos do preço interno $(-0,93$ a $-0,49)$ e da renda interna $(-0,16$ a $-1,94)$. O efeito negativo do preço interno preço interno contraria o pressuposto deste trabalho de que a elevação desse preço - de origem do lado da oferta - conteria o consumo e, assim, permitiria maior exportação. Parece que, no caso desses produtos da pecuária, uma elevação de preço provavelmente devido a um aumento de demanda - puxaria o produto para o mercado interno, reduzindo a exportação. Outro resultado importante foi o impacto da exportação negativo sobre a atratividade $(-0,65$ a $-0,60)$.

Pela decomposição da variância dos erros de previsão, as exportações de produtos de origem animal são explicadas em grande parte por elas mesmas. Em seguida, pela atratividade, o preço interno, a renda externa e a renda interna.

As importações de fertilizantes mostram-se altamente exógenas, indicando que vêm seguindo uma tendência já há algum tempo, caracterizando uma dependência do País em relação ao mercado externo. Num menor grau, observa-se a influência da atratividade $(0,55$ a 0,10$)$ e pelos preços internos dos produtos agrícolas (1,37 a 0,54) sobre as importações. Conclui-se, assim, que a demanda por importações de fertilizantes seria inelástica em relação aos preços. Já os preços internos dos fertilizantes, reduziriam as importações $(-0,09$ a -1,19). No entanto, esse efeito deve ser considerado apenas como potencialmente observável. De qualquer forma, a atratividade é responsável por apenas $10 \%$ de poder explanatório e os preços internos dos produtos agrícolas 
por $8,1 \%$ da variância de previsão das importações de fertilizantes.

Os resultados da pesquisa indicam que o comportamento do agronegócio brasileiro no front externo está bastante vinculado ao câmbio e aos preços externos, aqui sintetizados como atratividade da transação.

Com o crescimento da produtividade seria possível, em tese, a continuação indefinida do processo de sustentabilidade de um sistema de agronegócio ancorado no mercado externo. Todavia, alguns estudos têm demonstrado que a produtividade já não vem crescendo ao mesmo ritmo da década passada, seja pela queda da rentabilidade da agropecuária (que contém a adoção de tecnologia), seja pela redução dos investimentos em ciência e desenvolvimento (que contém o fluxo de novas tecnologias).

\section{Referências bibliográficas}

ALVES, L.R.A. A reestruturação da cotonicultura no Brasil: fatores econômicos, institucionais e tecnológicos. 2006. 122 p. Tese (Doutorado em Economia Aplicada) da Escola Superior de Agricultura "Luiz de Queiróz”, Universidade de São Paulo, Piracicaba, 2006.

BARROS, G.S.C.; BACCHI, M.R.P.; BURNQUIST, H.L. Estimação de equações de oferta de exportação de produtos agropecuários para o Brasil (1992-2000). Brasília: Instituto de Pesquisa em Economia Aplicada, 2002. 53 p. (IPEA. Texto para discussão, 865).

BARROS, G.S.C.; FURTUOSO, M.C.; GUILHOTO, J.J.M. O agronegócio na economia brasileira: 1994 a 1999. Piracicaba: Cepea/Esalq; Brasília: CNA, 2000. Disponível em: < http://www.cepea.esalq.usp.br/pib/ other/relatorio_metodologico.pdf > . Acesso em: 5 set. 2004.

BRASIL. Ministério do Desenvolvimento, da Indústria e do Comércio Exterior. Sistema de Análise de Informações de Comércio Exterior - Aliceweb. Disponível em: < http://www.aliceweb.desenvolvimento. gov.br $>$. Acesso em: 4 fev. 2006.

BLANCHARD, O.J.; QUAH, D. The dynamic effects of aggregate demand and supply disturbances. The American Economic Review, New York, v. 79, n. 4, p. 655-673, Sep. 1989. 
BRANSON, W.H. Macroeconomia: teoria e política. Lisboa: Fundação Calouste Gulbekian, 1979. 793 p.

CENTRO DE ESTUDOS AVANÇADOS EM ECONOMIA APLICADA (CEPEA). Índices de exportação agro. Disponível em: < http://www.cepea.esalq.usp.br/macro/ > . Acesso em: 5 maio 2006.

DICKEY, D.A.; FULLER,W.A. Likelihood ratio statistics for autoregressive time series with a unit root. Econometrica, Cambrigde, v. 49, n. 4, p. 1057-1072, July 1981.

ENDERS, W. Aplied econometric time series. New York: John Wiley \& Sons, 1995. $435 \mathrm{p}$.

ENGLE, R.F.; GRANGER, C.W.J. Co-integration and error correction representation, estimation and testing. Econometrica, Cambridge, $v$. 55, n. 2, p. 251-276, 1987.

FULLER, W.A. Introduction to statistical time series. New York: John Wiley, 1976. 424 p.

FAO. FAO corporate statistical databases. Disponível em: < http://faostat.fao.org/site/336/default.aspx > . Acesso em: 15 abr. 2006.

FUNDAÇÃO GETÚlIO VARGAS (FGV). FGV Dados. Disponível em: < http://fgvdados.fgv.br > . Acesso em: 25 abr. 2006.

INSTITUTO DE PESQUISA EM ECONOMIA APLICADA (IPEA). Ipeadata. Diponível em: <http://www.ipeadata.gov.br/ipeaweb.dll/ ipeadata?589122968 > . Acesso em: 27 abr. 2006.

JOHANSEN, S. Statistical analysis of cointegration vectors. Jornal of Economisc Dyanamics and Control, v. 12, n. 2/3, p. 231-254, 1988.

MIRANDA, S.H.G. Quantificação dos efeitos das barreiras não-tarifárias sobre as exportações brasileiras de carne bovina. 2001. 254 p. Tese (Doutorado em Economia Aplicada) da Escola Superior de Agricultura "Luiz de Queiroz", Universidade de São Paulo, Piracicaba, 2001.

NUNES, E.; CONTINI, E. Complexo agroindustrial brasileiro: caracterização e dimensionamento. Brasília: Associação Brasileira de Agribusiness - ABAG, 2000. 109 p. 
SIMS, C.A. Macroeconomics and reality. Econometrica, Cambridge, v. 48, n. 1, p. 1-48, Jan. 1980.

SPOLADOR, H.F.S. Impactos dinâmicos dos choques de oferta e demanda sobre a agricultura brasileira. 2006. 108 p. Tese (Doutorado em Economia Aplicada) da Escola Superior de Agricultura "Luiz de Queiróz”, Universidade de São Paulo, Piracicaba, 2006.

TOMICH, F.A.; MAGALHÃES, L.C.G.; SILVEIRA, F.G. Desempenho do comércio internacional e a competitividade do agronegócio brasileiro: avaliação da década de 1990 e cenários. In: GASQUES, J.G.; CONCEIÇÃO, J.C.P.R. (Org.). Transformações da agricultura e políticas públicas. Brasília: Ipea, 2001. p. 340-372.

VICENTE, J.R.; GONÇALVES, J.S.; MARTIN, N.B.; ANEFALOS, L.C.; SOUZA, S.A.M. Sistema de importações e exportações dos agronegócios (Sistema IEA): conceituação e análise de resultados, 1997-2001. São Paulo: Governo do Estado de São Paulo, Secretaria de Agricultura e Abastecimento, Agência Paulista de Tecnologia dos Agronegócios, maio 2002. $356 \mathrm{p}$. 